\title{
INTRODUCCIÓN A TRAVÉS DE LA FIGURA DE ROBERT CASTEL
}

\section{INTRODUCTION THROUGH THE FIGURE OF ROBERT CASTEL}

\author{
Eva María Sotomayor Morales esotoma@ujaen.es \\ Universidad de Jaén. España.
}
María LUISA GRande Gascón mlgrande@ujaen.es
Universidad de Jaén. España.

En un contexto social imbuido de vertiginosos cambios que confluyen en situaciones de degradación social cada vez más evidentes, las organizaciones, entendidas éstas como aquellas del ámbito privado y público y desde las grandes y pequeñas corporaciones, ponen a prueba los principios que años antes han venido consolidando acerca del papel desempeñado para paliar la pobreza, la desigualdad e impulsar los progresos sociales. Pero en los actuales contextos de incertidumbre, donde muchos pilares del bienestar parecen haber comenzado a desmoronarse, la responsabilidad asumida por las empresas, las administraciones públicas y organizaciones de todo tipo comienza a cuestionarse y se deja evidenciar en un contexto plagado de grandes transformaciones y perniciosas amenazas como el desempleo, la pobreza, las desigualdades, la precariedad y, sobre todo, la pérdida de confianza de la ciudadanía.

Para aquellos colectivos que tradicionalmente han ocupado espacios degradados en la escala de los posicionamientos sociales, como las personas con discapacidad psíquica e intelectual, el abanico de necesidades comienza a desplazarse al competir tácita o simbólicamente con otros que comienzan a estar claramente desfavorecidos, como los jóvenes, los desempleados o, en general, las personas de clase media que, con la crisis económica, han debilitado su poder adquisitivo.

Por ende, desde la pérdida generalizada de bienestar, y desde el desmoronamiento de los pilares básicos de apoyo y solidaridad hacia los colectivos desfavorecidos, la visión y el debate deben reanudarse, ya que la lectura sociológica queda obligada a retomar interpretaciones y análisis que comienzan a quedar obsoletos.

Este es el sentido que motiva principalmente este monográfico: el redefinir algunas de las nuevas situaciones sociales que en los últimos años han tenido lugar en los contextos sociales privilegiados, aquellos a quienes se les suponía habían alcanzado una situación de privilegio en las demandas y prestaciones sociales y que ahora están experimentando un retroceso. Y esta visión se realiza desde el análisis de la influencia 
y responsabilidad social de las organizaciones en los ámbitos de los derechos humanos, desde la salud, desde la administración local y de los movimientos sociales, todos estos ámbitos focalizando específicamente al colectivo de personas con discapacidad. Estas organizaciones que han venido a responsabilizarse en cierto modo de los avances sociales desde una comprensión ética y humanizadora.

En este sentido, no cabe duda de que la pobreza y las carencias humanas están estrechamente ligadas al término Responsabilidad Social de las Organizaciones por diversas razones. La primera de ellas la encontramos en la historia socieconómica del siglo pasado, en el cual grandes acciones de filantropía fueron protagonizadas por insignes hombres de negocios que observaban el deterioro de una sociedad que había alcanzado grandes niveles de bienestar en los años 30, pero que se deprimía a causa de un cataclismo económico y financiero de impacto similar al actual; e incluso en sociedades anteriores de finales del siglo XIX, en las cuales el mercado de trabajo emergente de la industrialización comenzaba a condicionar la posición social —cada vez más degradada - de la clase trabajadora. Desde este momento hasta la actualidad, la ética empresarial y la responsabilidad social de las organizaciones a las que se le había atribuido un unidireccional fin de lucro, pasa a ocupar un debate y una realidad indiscutible en la cual emergen pactos mundiales, códigos de buen gobierno corporativo, buenas prácticas de la empresa ciudadana y una amalgama de indicadores y medidas estándar que, junto a un desarrollo científico de la materia, consolidan lo que hay entendemos por Responsabilidad Social Corporativa o Responsabilidad Social de las Empresas.

En este contexto argumental, se ha realizado el presente monográfico Procesos de exclusión en el ámbito de la Responsabilidad Social de las Organizaciones. Y habiendo anteriormente descrito su origen temático, el origen estructural y humano del mismo ha venido a solidificarse a través de los debates que tuvieron su punto de partida en una reunión científica, el III Congreso Internacional sobre Discapacidad Intelectual, que celebramos en la Universidad de Jaén en febrero de 2011, bajo el lema "Para avanzar en la Responsabilidad Social: inclusión social, autonomía y sensibilización". La conferencia inaugural y posterior hilo conductor de los debates científicos estuvieron a cargo del sociólogo francés Robert Castel, quien en "Les risques d'exclusion sociale dans un contexte d'eincertitudes", y en la que expuso sus postulados, advirtiendo que la marginación social afectaba cada vez más a más categorías sociales, afectando ello a la posición de las personas con discapacidades psíquicas en este orden de posicionamientos sociales, y en parte debido a las grandes transformaciones sociales que estaban teniendo lugar en la mayoría de los países de Europa.

A partir de esta conferencia se generó una línea de debate cientíico, no sólo a través de las ponencias, mesas redondas y grupos de trabajo del Congreso, sino posteriormente en reuniones y conversaciones de investigadores con inquietudes paralelas. E hilo conductor fue el abordaje de la exclusión social desde diferentes perspectivas analíticas, fundamentalmente focalizando los efectos en uno de los colectivos que padecen las consecuencias más perniciosas de las desigualdades y discriminaciones latentes: las personas con diversidad funcional o discapacidad y, dentro de estas, aquellas situadas más al vértice de los procesos exclusógenos: las personas con discapacidad intelectual 
o psíquica. La experiencia relatada por Robert Castel en su conferencia fue fundamental para partir desde un punto de vista histórico, de un pasado reciente y aún vivo a través de sus generaciones, desde finales de los años 60 y durante los 70 , en los cuales tuvo unas intensas relaciones con algunos colegas españoles y en los cuales trabajó durante unos años sobre la psiquiatría y la salud mental, no sólo desde el ámbito académico, sino también participando activamente en el movimiento que bautizaron como "la antipsiquiatría", fundando lo que él denominaba un "gran grupo" llamado "La Red interna de alternativa a la psiquiatría", en concreto con algunos colegas italianos, como el psiquiatra Franco Basaglion, cuya acción culminó con el voto de la Ley 180 en Italia, que abolió los hospitales psiquiátricos en ese país.

Castel rememoró cómo pugnó junto a sus colegas en contra la segregación social de los enfermos mentales cuyo internamiento en los hospitales psiquiátricos, a menudo de por vida, constituía, según él, "la manifestación más escandalosa de la marginalidad". Su pensamiento y argumentos teóricos en torno a estos colectivos, en cierto modo bastantes desconocidos en relación a la obra de Castel, se fraguaron en torno al año 1973 en su viaje a Barcelona, estando España todavía bajo el régimen franquista, a causa de que un psiquiatra español, Ramón García, fue procesado por tratar de abrir el hospital psiquiátrico de Barcelona y "desinstitucionalizar "a los enfermos mentales.

En ello insistía el profesor Castel, y en parte sus últimos escritos, apelando a la cautela de construir la explicación sociológica, desde el realismo pero sin dejar de pensar en el pasado reciente, cuando en Europa, y años más tarde en España, la sociedad se encontraba en un periodo de expansión económica y progreso social extraordinario, situación que consolidó grandes contradicciones que perduran en la realidad actual, pero a raíz de la cual se constituye la principal diferencia. Por aquel entonces, en un contexto en el cual se celebraba el progreso, a los enfermos de los hospitales psiquiátricos se les trataba de una manera que recordaba más a la Edad Media que a la sociedad civilizada de la cual los ciudadanos se vanagloriaban por el mero hecho de pertenecer a ella.

Esta conferencia ha sido la base del primer texto del monográfico, "Riesgos de exclusión en un contexto de incertidumbre", en el cual Castel realiza una disertación sobre la gran transformación de los procesos de exclusión social que, agravados por la actual crisis económica internacional que está afectando a los países con Índice de Desarrollo Humano alto, tiene como resultado una multiplicación de las categorías sociales con dificultades de integración. Y ese es precisamente el punto de interés de la conferencia, de cómo el colectivo de personas con discapacidad psíquica, tradicionalmente situado en una posición de desventaja social, ha sido desplazado por colectivos que, con anterioridad a las grandes transformaciones sociales acaecidas en los últimos años, se situaban en una posición de mayor privilegio.

El citado texto de Robert Castel ha sido la base argumental de los siguientes cinco artículos que, aunque todos ellos tienen un mismo hilo conductor, abordan desde diferentes aristas el tema de los procesos de exclusión social que se están generando en los últimos años. En el segundo texto presentado en este trabajo, "Ética empresarial y sociedades en crisis desde un enfoque axiológico", firmado por Sotomayor y Cámara, 
se realiza un análisis sociológico de la función social que las empresas tienen en la sociedad actual y, en concreto, en las sociedades en crisis, en las cuales emergen las necesidades y carencias sociales. Ello se realiza empleando un enfoque axiológico, analizando el rol social y la ética empresarial desde las necesidades y los valores presentes en las sociedades, tanto en los ámbitos normativos, como en el orden de las demandas sociales y los elementos analíticos resultado de la comparación con sociedades análogas, como la de la Gran Depresión de 1929, al referirse este texto a los procesos de exclusión social en el ámbito de la responsabilidad social de las organizaciones, tema central del monográfico, partiendo de la teoría de Castel y de la construcción de sus argumentos científicos a través del cual los grupos más desfavorecidos se desplazan hacia posiciones sociales menos ventajosas; el análisis de las posiciones sociales de las empresas en las épocas en las cuales se incrementa la desigualdad, la exclusión social y la pérdida de derechos fundamentales de los ciudadanos medios emerge como punto central del debate científico. En este sentido, con la crisis iniciada en otoño de 2007, los valores que legitiman la empresa se fracturan y fluye la información que les atribuye la responsabilidad de los "males sociales", adquiriendo relevancia los discursos culpabilizadores. Siendo estos aspectos cuestiones transmitidas pertinazmente a través de la mass media, esta inyección de información y una necesidad apremiante por parte de estas sociedades de buscar responsables directos de la crisis afecta a los valores que determinarán las atribuciones que los grupos sociales realizan hacia las empresas. En este plano axiológico, la ética está en estrecha interacción con los valores sociales a través de una representación social como eje central del papel que éstas, los empresarios y los líderes empresariales desempeñan en la sociedad y la interpretación de la acción, que conduce a una evolución de la visión de la organización y, en consecuencia, de su legitimación.

El tema de la responsabilidad social de las organizaciones, termina de perfilarse en el tercer texto, "Responsabilidad Social y discapacidad intelectual", firmado por Crowther y Duarte, que desciende desde el plano teórico a la cuestión más específica del colectivo central de debate, bajo el argumento de que la incorporación de este aspecto en la planificación corporativa es esencial para desarrollar cualquier negocio sostenible. Ello se muestra desde la revisión de los derechos humanos y de su importancia en los entornos empresariales, centrando su atención principalmente en la discapacidad intelectual, que a menudo se trata como un tema invisible y se elimina del discurso y de cualquier consideración en la estrategia corporativa; argumentando que los beneficios de incorporar una preocupación por la discapacidad intelectual en la planificación corporativa pesan más que las desventajas, no sólo en términos sociales y de capital humano sino también en términos financieros.

En el cuarto texto, "La salud y sus determinantes sociales; desigualdades y exclusión en la sociedad del siglo XXl", firmado por Palomino, Grande y Linares, se trata la responsabilidad social desde la perspectiva de la salud. En el mismo se realiza una revisión de los diferentes modelos teóricos que han abordado los determinantes sociales de la salud, haciendo especial hincapié en la cuestión del género y la influencia que éste tiene en las diferencias y desigualdades que existen en la salud de hombres y mujeres. Se parte de un 
concepto de desigualdad en éste ámbito, que alude al impacto que tienen sobre la distribución de la salud y la enfermedad en la población factores como la riqueza, la educación, la ocupación, el grupo racial o étnico, la residencia urbana o rural y las condiciones sociales del lugar en el que se vive o trabaja. El fenómeno de las desigualdades en salud se define por su carácter injusto y evitable, además de su ubicuidad, enorme magnitud, carácter gradual, tendencia creciente y persistente, y su carácter adaptativo. En este texto también se analiza la discapacidad como un importante factor de riesgo relacionado con la exclusión social, describiendo los principales obstáculos para este grupo, especialmente vulnerable, como la ausencia o insuficiencia de iniciativas relacionadas con el acceso a servicios básicos entre los que se incluye la atención a la salud.

En el quinto texto titulado "Las Tecnologías de la Información y la Comunicación como entorno de convergencia tecnológica. El design thinking aplicado a la discapacidad intelectual", firmado por De la Fuente y Hernández-Galán, se presentan las conclusiones de una investigación relacionada con el uso de las Tecnologías de la Información y Comunicación por parte de personas con discapacidad intelectual, como medio para aumentar su autonomía en las actividades básicas de la vida diaria, ofreciendo a las personas con barreras para el aprendizaje y la participación un entorno de convergencia tecnológica que ha cumplido con las características de la accesibilidad universal y de diseño para todos; dicha investigación ha sido auspiciada bajo la política de la responsabilidad social de la administración local. Gracias a ella, las personas participantes aumentaron hasta un $10 \%$ en su autonomía, por lo que el software diseñado bajo el parámetro del design thinking demostró ser eficaz.

En el último texto, "Movimientos Sociales, Responsabilidad Corporativa e Inclusión Social en la Globalización", firmado por Alberich, se realiza una breve descripción histórica de los orígenes de la era actual de la globalización neoliberal y la relación que ha tenido con el propio nacimiento de la Responsabilidad Social Corporativa. Se indica cómo ya en los años setenta del pasado siglo se inauguró un ciclo de crisis socioeconómicas sucesivas que prácticamente no se abandona hasta el comienzo en 2007/8 de la actual, marcadas por un capitalismo especulativo que es especialmente creciente en las dos últimas décadas y que se desarrolla al hilo de esa globalización neoliberal. En el mismo se describen a continuación las cuatro posiciones dominantes en los sistemas político-económicos actuales y, cómo desde uno de ellos, el de capitalismo auto-reglado, se potencia un Estado de Bienestar a la baja y una Responsabilidad Social al alza. También se analizan las variantes principales de la Responsabilidad Social Corporativa y cómo son utilizadas por asociaciones no lucrativas y movimientos sociales, desde diferentes posturas y en sus relaciones con los ámbitos del poder público y privado, describiendo más en concreto el ejemplo de las asociaciones de acción social de la discapacidad. Estas entidades han sabido actuar de una forma reivindicativa y movilizadora a la vez que han ido paulatinamente utilizando numerosas formas de colaboración con administraciones públicas y con empresas privadas, conformando un buen ejemplo de reflexión-acción, que aúna pensamiento complejo con acciones superadoras que no se mueven en la simplicidad del dilema de decir sí o no a las relaciones con el mundo económico y del mercado. 
Con estos seis textos presentados en el monográfico se puede comprender el debate surgido a raíz de los seminarios científicos realizados en el III Congreso Internacional sobre Discapacidad Intelectual, en los cuales surgió un grupo de trabajo bajo las directrices argumentales de Robert Castel que animaron a los participantes a presentar los resultados de las investigaciones que habían realizado en este campo y que aportaban una visión complementaria al análisis de la exclusión social.

Quisiéramos agradecer, a los impulsores del Congreso, a la Asociación Aprompsi, que junto con la Universidad de Jaén, realizaron un esfuerzo para que éste pudiera llevarse a cabo. A esta organización, que incansablemente pugna por la inclusión de las personas con discapacidad intelectual, hemos de agradecer el punto de partida que supuso para el Congreso, por el cual pudieron materializarse los siguientes intercambios de investigadores y profesores. También queremos destacar, en estos tiempos difíciles, el apoyo económico que nos prestaron diferentes organizaciones, como la Fundación Mapfre.

Por último, no quisiéramos finalizar esta presentación sin realizar una alusión a la memoria de Robert Castel, que falleció el pasado 12 de marzo de 2013, y que nos sumió a todos los investigadores en un profundo pesar y nos dejó con la ingrata sensación de no poder disfrutar, junto a él, de la edición de estos textos. Como ya tuvimos la oportunidad de expresar en la necrológica firmada por Sotomayor, en un plano más neutral o impersonal, Castel destacaba sin duda por ser un intelectual de nuestro tiempo que supo analizar los cambios que afectarían a futuras generaciones. Por otro lado, en el plano humano era un ejemplo admirable de adaptación, de humildad y, por ende, de sabiduría. Por tanto, queremos dedicarle estos textos, con todo el agradecimiento por haber guiado nuestro trabajo y haber focalizado la visión anteriormente manifestada de que, en realidad, los diferentes costados de las carencias humanas, ya sea nombrado bajo el concepto de la exclusión social o, como el mismo prefería decir, de la precariedad o vulnerabilidad humana, son en realidad manifestaciones de la gran degradación social a la cual estamos asistiendo en los últimos años.

Eva María Sotomayor Morales es Doctora en sociología en el año 2004 y habilitada por la ANECA como profesora Titular de Universidad con fecha de 4 de septiembre de 2012. Actualmente profesora contratada doctora del Departamento de Psicología de la Universidad de Jaén (Área de Trabajo Social y Servicios Sociales). Es miembro del Grupo de Investigación PAl: Género, dependencia y exclusión social y del Grupo de Investigación sobre Tendencias Sociales de la UNED. Sus publicaciones se relacionan con los temas de pobreza, exclusión social y desi-gualdades sociales, en consonancia con sus líneas de investigación. Ha sido la Directora del III Congreso Internacional sobre Discapacidad Intelectual celebrado en la Universidad de Jaén en febrero de 2011.

María Luisa Grande Gascón es enfermera, socióloga, doctora por la Universidad de Jaén. Actualmente es profesora titular e imparte docencia en la Facultad de Ciencias de la Salud de la Universidad de Jaén. Sus líneas de investigación actuales son: discapacidad, género y salud. Ha participado como investigadora en diferentes proyectos tanto nacionales como internacionales, en países como Marruecos, Colombia, Mali, Brasil, Bolivia y Venezuela. Asimismo, es docente en Master oficiales relacionados con la dependencia y la discapacidad.

RECIBIDO: 15/01/2014

ACEPTADO: 15/02/2014 